\title{
Study on Sediment problem in Drainage project of Tianwan Power plant Wendan $\mathrm{Li}^{1}$, Xiaohui Tian ${ }^{2}$, Mengguo $\mathrm{Li}^{2}$ \\ ${ }^{1}$ Tianjin Research institute for water transport engineering, M.O.T, Tianjin, 300456, China \\ ${ }^{2}$ The tourism Bureau of Yantai E\&T Development Area, Yantai, 264006, China
}

Keywords: drainage project, sediment, year deposition, sudden deposition.

\begin{abstract}
The deposition problem related to the drainage project of Tianwan Power Plant was studied in this paper. Firstly, the hydrology and sediment environments in the ocean area near the project are analysed. Secondly, based on the observed data in 2010, two-dimensional model of wave, tidal current and sediment transport is used to study the deposition of drainage project. Lastly, the year deposition and sudden deposition is given in this paper.
\end{abstract}

\section{Introduction}

The Tianwan power plant is located at Lianyungang, south of Lianyungang Port (see Figure.1), which construction of 1st and 2nd unit commenced on 20 October 1999 and the commercial operations began on May 17 and August 16 2007, respectively. Without shutdown, it has brought nicer social efficiency. The construction for the 3rd-8th units has started, each rated at 1,000 MW capacities.

The intake and drainage project of the Tianwan power plant is located at Yangshan Island and Shaoxiang River respectively. The main purpose in this paper is to study the sediment problem after the construction of drainage project.

\section{Hydrology and Sediment environment}

\section{Tide and tidal}

The tide in the ocean area near the project site is semidiurnal dominant mixed tide. The mean tidal range is $3.66 \mathrm{~m}$, which means the project sea area is under the action of an intermediate tide. The tidal current presents counter clockwise rotation in the outer region of the ocean area near the project site. The flood current is southward with the dominate direction of SSW, and the ebb current is northward, with dominate direction of NNE. According to the observed data in 07/1997, 07/2005, $01 / 2006$ and 01/2010, the mean velocities at different stations during flood or ebb increase with the tidal ranges and with the distance away from the coastline. The mean velocity of the flood current during spring tide is in the range of $0.12-0.45 \mathrm{~m} / \mathrm{s}$. The velocity near the eastern entrance of Lianyungang Port is relatively larger, with the maximum value in the range of $0.55-0.88 \mathrm{~m} / \mathrm{s}$ for flood current. 


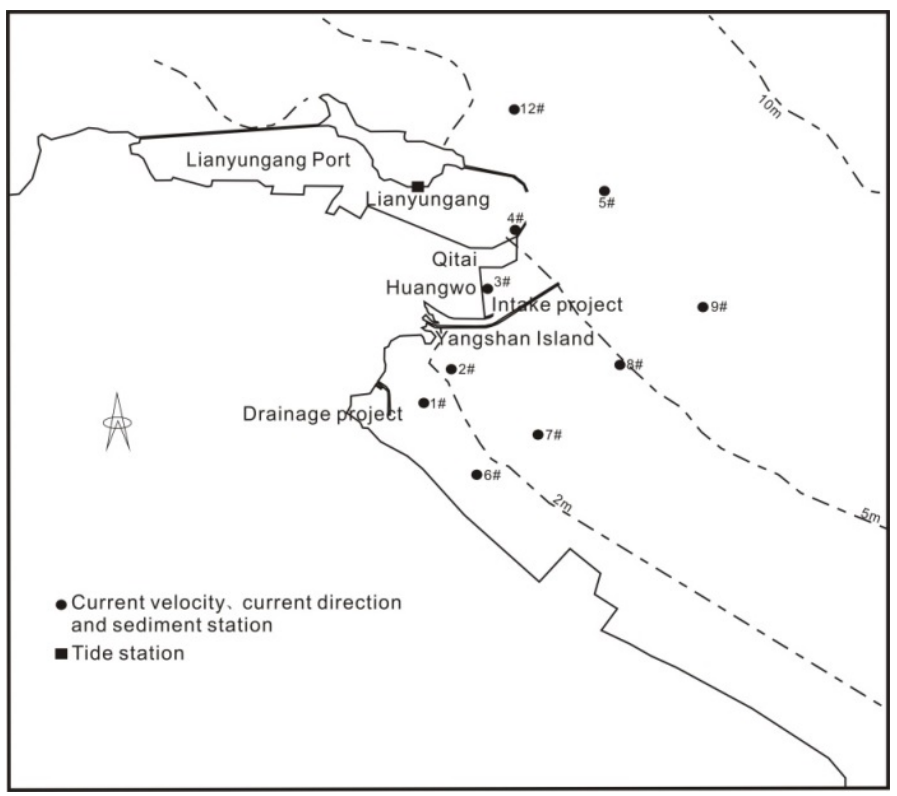

Fig.1 Sketch of project area

Wave

The maximum wave height occurs in winter and the minimum wave height occurs during the period from May to July. The directions of prevailing waves are NE and E, with the occurrence frequencies of $26.41 \%$ and $18.40 \%$. The large waves mainly presents in the direction of NNE and NE. The maximum wave height is $5.0 \mathrm{~m}$.

\section{Sediment enviroment}

According to the observed data collected during 1997-1998 at the permanent station near the project site, the sediment concentration in the ocean area near the project site is about $0.43 \mathrm{~kg} / \mathrm{m}^{3}$.

\section{Grain size of suspended load}

The variation of the median diameter of the suspended load is small. According to the observed data in 1997, 2005 and 2010, the median diameter d50 is in the range of 0.004-0.01 mm.

\section{Seabed sediment}

According to the observed data in 1998, the sediments in the ocean area near the project site are mainly silty clay and clayey silt. According to the observed data in 09/2005, the sediments in the ocean area near the project site are mainly sandy silt and clayey silt, which demonstrate that siltation is mainly from the suspended load.

\section{Two-dimensional mathematical models}

The tidal current and sediment transport in the ocean area near the Tianwan nuclear power plant are simulated using the TK-2D model, which is developed by Tianjin Research Institute for Water Transport Engineering, M.O.T. and has been applied in many projects. The equations and difference method see reference [1].

\section{Drainage project}

A combination of culverts + drainage jetty + excavation open channel drainage way is used by drainage. Drainage diversion dike is converted to southwest through $522 \mathrm{~m}$ long are of $120^{\circ}$ based on North dyke of outlet, and is extended straight $694 \mathrm{~m}$; finally, a half-encircling dike is formed.

The drainages by open channel of 1 \# 2 \# units are formed by excavation, in which the excavation length is about $1270 \mathrm{~m}$, the bottom width is $60 \mathrm{~m}$, and the bottom elevation is $-3.5 \mathrm{~m}$. The drainages by open channel of 3 \# 4 \# units are also formed by excavation, in which the excavation length is about $1500 \mathrm{~m}$; the bottom width is $80 \mathrm{~m}$.

\section{Model foudation}

The size of computational domain is about $76.6 \mathrm{~km}$ in the east-west direction and $55 \mathrm{~km}$ in the north-south direction. The northern end is at $34^{\circ} 55^{\prime} \mathrm{N}$, and the eastern end is at $120^{\circ} 00^{\prime} \mathrm{E}$. 
The triangular grid is employed for the model. The numbers of the nodes and elements are 40890 and 80 748. The maximum distances between the neigh boring nodes are $1402.12 \mathrm{~m}$ and $9.04 \mathrm{~m}$.

\section{Hydrodynamic validation}

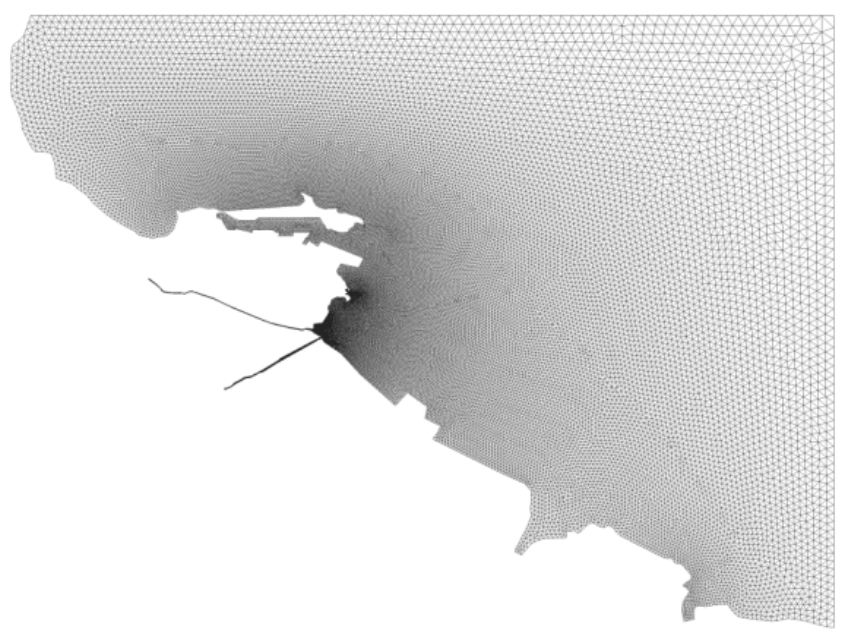

Fig.2 mesh of grid

The in-situ observation data of tidal elevation, current velocity and direction are utilized to validate the modal. The observation periods are 19/05/2011-20/05/2011 for the spring tide and 25/05/201126/05/2011 for the neap tide. The positions of the hydrometric stations are shown in Figure [1].

The comparison between the observed data and the calculated results are presented in reference [2] with respect to the tidal elevation, current velocity and direction. It is shown shat the calculated results agree well.

\section{Sediment validation}

1) Concentration under normal weather. The in-situ observed sediment concentration is utilized to validate the model. The comparison between the observed data and calculated results are presented in reference [3].

2) Annually averaged concentration. Average annual sediment concentration field calculation must not only consider the influence of the tide, but also consider the wave conditions. Therefore, the model is further validated with respect to the simulation of annually averaged concentration, where the effect of wave motion is included.

The calculated annually averaged concentration is simulated, which agree with the observed data at Yangshan island station and Shaoxiang River, i.e. $0.24 \mathrm{~kg} / \mathrm{m} 3$ and $0.43 \mathrm{~kg} / \mathrm{m}^{3}$, respectively (Figure.3).

3) Topography validation. The deposition of the intake open channel of second stage, 8 section underwater topography (1997 and 2005) and the deposition distribution along the Lianyungang channel are used to verification the siltation and erosion.Figure. 4 gives the validation of erosion from 2005 to 2011 by the one stage drainage project.

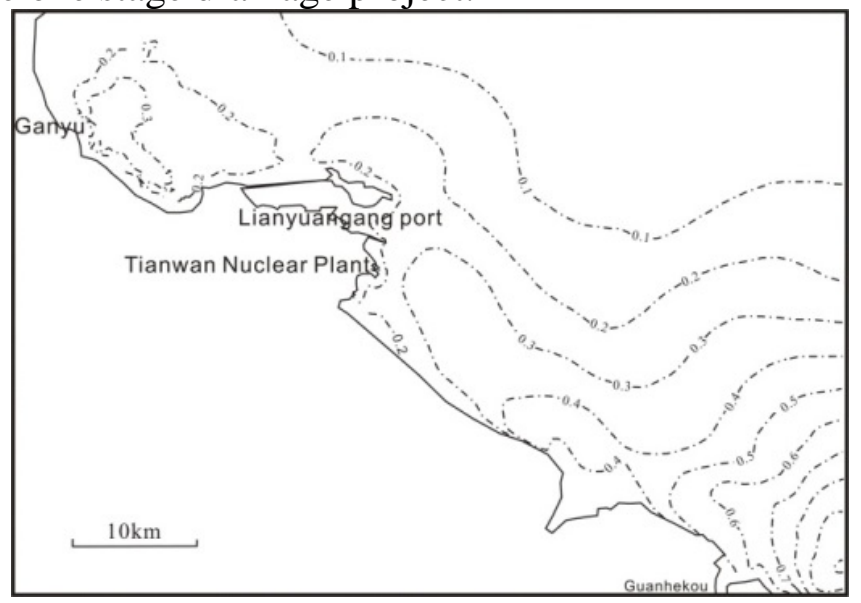

Fig.3 annual average sediment concentration 


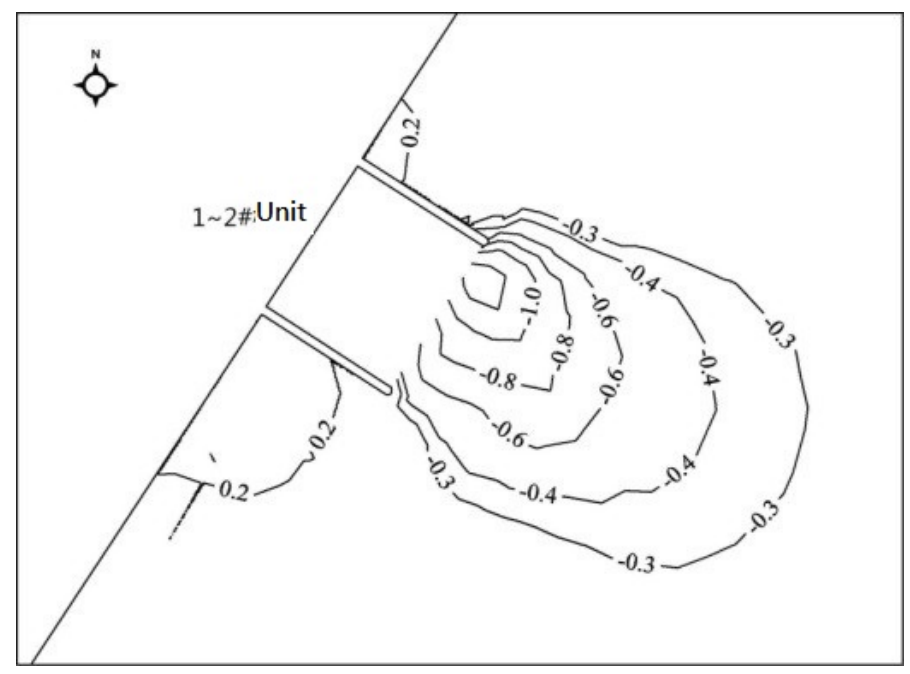

Fig.4 erosion validation

\section{Deposition results}

\section{Year deposition in the drainage channel}

From the flow field we can see that: by the influence of drainage and deflecting flow, there is some of circulating current on the west side of the dike. By computing, the year siltation intensity is $0.20 \mathrm{~m} / \mathrm{a}$.

\section{Sudden deposition in the drainage channel}

The sudden deposition is calculated by using 50-year frequency wave of ESE direction. By computing, the maximum siltation intensity is $0.07 \mathrm{~m}$.

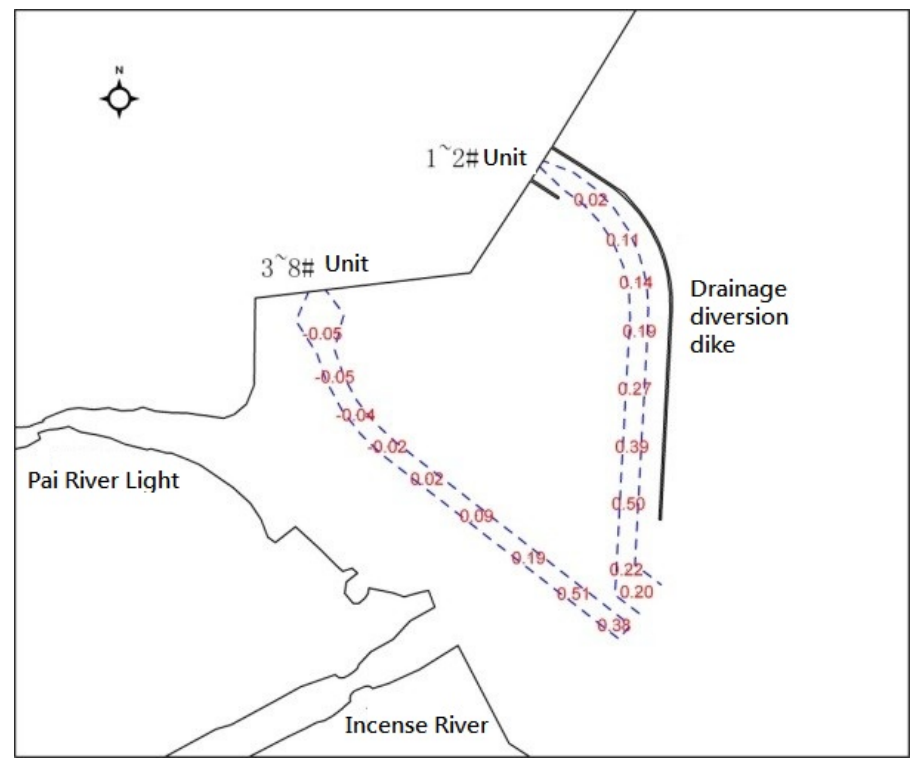

Fig.5 year deposition 


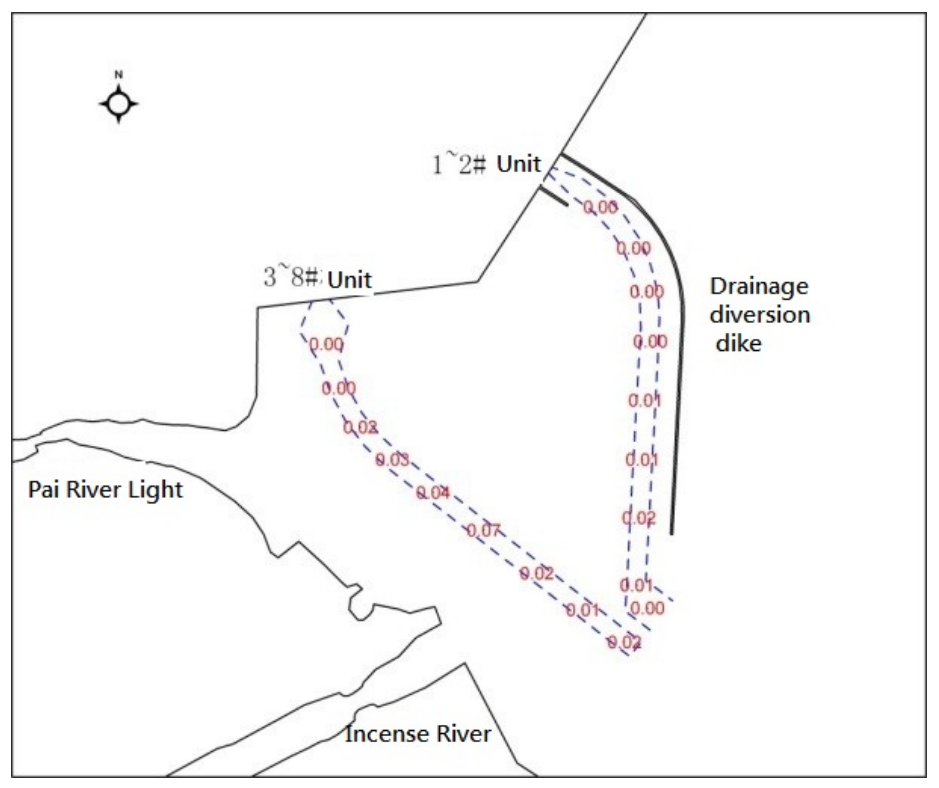

Fig.6 sudden deposition

\section{Erision at the area of entrance}

From the flow field we can see that: At ebb tide, the waters velocity increased significantly near the dike head. By computing, the maximum erosion intensity is $1.0 \mathrm{~m}$ under equilibrium condition.

\section{Conclusions}

The sediment problem related to the drainage project of Tianwan Power Plant was studied in this paper. It is showing that:

(1)From the flow field we can see that: by the influence of drainage and deflecting flow, there are some of circulating current on the west side of the dike. By computing, the year siltation intensity is $0.20 \mathrm{~m} / \mathrm{a}$.

(2)The sudden deposition is calculated by using 50-year frequency wave of ESE direction. By computing, the maximum siltation intensity is $0.07 \mathrm{~m}$.

(3)From the flow field we can see that: At ebb tide, the waters velocity increased significantly near the dike head. By computing, the maximum erosion intensity is $1.0 \mathrm{~m}$ under equilibrium condition.

\section{References}

[1] Li Mengguo, Zhang Huaqing.Study on multi-function mathematical model software package TK-D and its application for coast and estuary [J].Journal of waterway and harbour, 2006, 27(1):5156.

[2] Li Mengguo, Zheng Jingyun. Introduction to chinatide software for tide prediction in china seas. Journal of waterway and harbour, 2007, 28(1):65-68.

[3] Li Wendan, Zhao Hongbo. Investigation of the tidal current, wave and sediment transport for the expansion projects of drainage in the Tianwan power plant. Tianjin Research Institute for Water Transport Engineering, M.O.T, 2013. 